\title{
Performance Evaluation of Jatropha Biodiesel Fuelled in C.I Engine
}

\author{
M.Ravindran ${ }^{1}$, M.Arun Kumar ${ }^{2}$, \\ ${ }^{1}$ Assistant Professor Of Mechanical Engineering Muthayammal Engineering College, Rasipuram, Namakkal \\ (Dt), Tamilnadu, India. \\ ${ }^{2}$ M.Ashikmohamed, Dakkili Saivamsi, S.Dharmalingam Ug Scholar Department Of Mechanical Engineering \\ Muthayammal Engineering College, Rasipuram, Namakkal (Dt), Tamilnadu, India.
}

\begin{abstract}
Continuous use of petroleum sourced fuels is now widely recognized as unsustainable because of depleting supplies and the contribution of these fuels to the accumulation of carbon dioxide and carbon monoxide in the environment. Renewable, carbon neutral, transport fuels are necessary for environmental and economic sustainability. Here we will compare the blend of sole fuel with biodiesel extracted by double stage trans-esterification process from Jatropha seed oil to study the performance characteristics and emission of diesel engine. In this study, Jatropha seed oil is used to extract the bio-diesel. The extracted bio diesel is blended with sole fuel and B25\%, B50\%, B75\% and B100\% has been selected. The investigation was carried out in the single cylinder water cooled diesel engine with the sole fuel blended with Jatropha seed oil and the engine performance and emission characteristics will be analyzed. From the experimental investigation it is observed that the brake thermal efficiency decreased for B25\% blend by $0.4 \%$ when compared to that of sole fuel. The CO, HC, NOx are found to decrease when compared to that of diesel fuel.
\end{abstract}

Keywords: Bio-diesel, Jatropha Oil and Trans-esterification Process.

\section{Introduction}

Ebtisam K. Heikal et al, (2013) described that using Jatropha curcas L. (JCL) as a feedstock for the production of bio-diesel is rapidly growing. The properties of the crop and its oil have persuaded investors and policy makers consider JCL as a substitute for fossil fuels to reduce greenhouse gas emissions. In this work, we give an overview of the currently available information on the different process steps of the production process of bio-diesel from JCL. Based on this collection of data and information the best available practice, the shortcomings and the potential environmental risks and benefits are discussed for each production step. This work concludes with a call for general precaution and for science to be applied.

Nurrul Rahmah Binti Mohd Yusoff et al, (2013) explained that Plant oil represents the potential substance as new source energy to yield the ester methyl (biodiesel) as substitution of diesel oil. Jatropha curcas is a plant of fast growing species and well known specifically for its tolerance to almost most tropical climate and soil types, hence it is suitable for land conservation. In this study, the biodiesel oil was produced by Jatropha Curcas Oil (JCO) through two stages process. In esterification process, the FFA was successfully lowered to $0.8 \%$ by used methanol with molar ratio $16: 1,1 \%$ catalyst of acid sulphuric $\left(\mathrm{H}_{2} \mathrm{SO}_{4}\right)$ at $64.5^{\circ} \mathrm{C}$ reaction temperature and at 120 minutes of reaction time. The transesterification was performed at 120 minute of reaction time, $1 \%$ for the catalyst concentration and molar ratio of $6: 1$ and 9:1. The physical properties were investigated in term of kinematics viscosity, density, acid value and flash point. The best yield of biodiesel at 92 $\%$ was obtained with molar ratio 6:1.

Nirza Fabiola Castro Gonzales, (2016) studied that the problems encountered in all documented global experiences of cultivating the Jatropha curcas plant, covering 22 case studies. Influential components of the biodiesel production (stakeholders like government, farmers and enterprises as well as resources such as land and water) and how they are interconnected are pinpointed. In addition, the article gives recommendations to the main actors under ecological and socio-economic criteria to ensure a sustainable production of J. curcas oil in regions with appropriate climatic conditions for the plant's viability. Hence, this analysis of experiences discusses the following questions: What are the reasons and factors for the previous unsuccessful and unsustainable cultivation of J. curcas for producing biodiesel? Can it be lucrative and simultaneously achieve poverty alleviation/job creation under the constraints of efficient use of resources (land and water)?

Limited resources of conventional fuels such as petrodiesel have led to the search for alternative fuels. Recently, there has been a growing concern about the increasing air pollution caused by the combustion of petrodiesel. In addition, depleting resources of conventional fuels has caused an increase in its price. Biodiesel is an alternative fuel produced from renewable sources such as vegetable oil. It has a proven performance for air pollution reduction. However, the price of biodiesel is presently more as compared to petrodiesel. 
In recent years, biodiesel has gained international attention as a source of alternative fuel due to characteristics like high degradability, no toxicity, and low emission of carbon monoxide, particulate matter and unburned hydrocarbons. Biodiesel is a mixture of alkyl esters and it can be used in conventional compression ignitions engines, which need almost no modification. As well, biodiesel can be used as heating oil and as fuel. So far, this alternative fuel has been successfully produced by transesterification of vegetable oils and animal fats using homogeneous basic catalysts (mainly sodium or potassium hydroxide dissolved in methanol). Traditional homogeneous catalysts (basic or acid) possess advantages including high activity (complete conversion within $1 \mathrm{~h}$ ) and mild reaction conditions (from 40 to $65{ }^{\circ} \mathrm{C}$ and atmospheric pressure). However, the use of homogeneous catalysts leads to soap production. Besides, in the homogeneous process the catalyst is consumed thus reducing the catalytic efficiency. This causes an increase in viscosity and the formation of gels. In addition, the method for the removal of the catalyst after reaction is technically difficult and a large amount of wastewater is produced in order to separate and clean the products, which increases the overall cost of the process. Thus, the total cost of the biodiesel production based on homogeneous catalysis, is not yet sufficiently competitive as compared to the cost of diesel production from petroleum.

An alternative is the development of heterogeneous catalysts that could eliminate the additional running costs associated with the aforementioned stages of separation and purification. In addition, the use of heterogeneous catalysts does not produce soap through free fatty acid neutralization and triglyceride saponification. Therefore, development of efficient heterogeneous catalysts is important since opens up the possibility of another pathway for biodiesel production. The efficiency of the heterogeneous process depends, however, on several variables such as type of oil, molar ratio alcohol to oil, temperature and catalyst type. So, one among alternate production methods of biodiesel is catalytic cracking to improve quality of oil. This process is selected for production of biodiesel from mango seed oil.

Environmental pollution is very serious problem for our human beings and flora-fauna. The environment is polluted day by day from industrial emissions and road vehicles emissions. Petrol engine and diesel engine produced different types of harmful gases during combustion like $\mathrm{NO}_{\mathrm{x}}, \mathrm{CO}, \mathrm{CO}_{2}, \mathrm{HC}$ and some quantity $\mathrm{SO}_{x}$ due to incomplete combustion. These gases are produced by different engine factor such as piston bowl geometry, injection timing, compression ratio etc. These entire factors also affect the combustion efficiency, fuel consumption and engine brake power. To reduce the emissions engine manufacturers try to best design, the combustion chamber and other level. At combustion chamber geometry design to reduce the $\mathrm{NO}_{\mathrm{x}}$ many researchers studied the different piston bowl geometry.

Flow phenomena in internal combustion (IC) engines are extremely complex, and the flow field is further complicated by the presence of swirl, squish, tumble and chemical reactions. A complete understanding of the physical processes of fluid motion in combustion is essential in developing efficient engine design and control diagnostics.

Diesel engines have been greatly improved in terms of efficiency and reduced emission level. However, the combustion process also depends highly on an efficient fuel-air mixture, particularly in high-speed direct-injection diesel engines. Among these processes, the flow conditions inside the cylinder at the end of the compression stroke and near the top dead center are critical for fuel air mixing, wall heat transfer and engine performance improvement. The mixing process is affected by the intake swirls, fuel injection system and combustion chamber configuration. Thus good engine operation requires fuel spray matching air movement and combustion chamber configuration.

Research on the production of biofuel from the fossil fuels are causing the global climate change due to catalytic cracking of mango seed oil has been well developed. This method is able to crack complex hydrocarbons to yield less complex structures. With the help of a catalyst, the reaction may be conducted at a lower temperature and pressure; moreover the quality and quantity of the products may be enhanced. In the catalytic cracking of vegetable oil to produce biofuel, the type and products' compositions are influenced by several factors, such as time, temperature, flow rate of the raw materials and type of catalysts. Many types of catalyst have been used in the catalytic cracking to produce biofuel. The catalysts have been developed to be used in the catalytic cracking of vegetable oil to produce biofuel.

\section{TRANSESTERIFICATION PROCESS}

\section{Production Of Biodiesel}

Transesterification is also called alcoholysis, is the displacement of alcohol from on ester by another alcohol in a process similar to hydrolysis.

This process has been widely used to reduce the viscosity of triglycerides. The transesterification reaction is represented by the general equation

$\mathrm{R}$ COOR' + R" R COOR" + R' OH

If methanol is used in the above reaction, it is formed as methanolysis. The reaction of glyceride with methanol is represent by the general equation triglycerides are readily transesterified in the presence of alkaline catalyst at 
atmospheric pressure and at a temperature of approximately go to $70^{\circ} \mathrm{C}$ with an excess of methanol. The mixture at end of the reaction is allowed to settle. The lower glycerol layer is drawn off while the upper methyl ester layer is washed to remove entrained glycerol and is then processed further.

The excess methanol is recovered by distillation and sent to rectifying column for purification and recycled. The transesterification works well when the starting oil is of light quantity. However, quite often low quality oils are used as raw materials for biodiesel preparation. In case where the free fatty acid content of the oil is above $4 \%$, difficulty arise due to formation of soaps which promote emulsification during the water working stage and at an FFA content above $2 \%$ he process becomes unworkable.

If the free fatty acid content of the oil is below $4 \%$ single stage process is adopted. If the free fatty acid content $\mathrm{s}$ greater than $4 \%$ double stage process is adopted.



Figure 2.1.Transesterification process

\subsection{EXPERIMENTAL SETUP}

\section{Experimental Setup And Procedure}

The experiment was conducted on Kirloskar TV-1 single cylinder direct injection (DI) diesel engine. Table 6.1 tabulates the specification of the engine while shows the schematic of the overall arrangement of the test engine. The engine was coupled to an eddy current dynamometer for load measurement and the smoke density was measured using a AVL smoke meter. NOx emission was measured using AVL Di-gas analyzer. The experiments were carried out in different phases.

Table 1: Specifications of test engine

\begin{tabular}{|l|l|}
\hline \multicolumn{1}{|c|}{ Type } & $\begin{array}{l}\text { Single cylinder, vertical, water } \\
\text { Cooled, 4-stroke diesel engine }\end{array}$ \\
\hline Bore & $87.5 \mathrm{~mm}$ \\
\hline Stroke & $110 \mathrm{~mm}$ \\
\hline Compression Ratio & $17.5: 1$ \\
\hline Orifice Diameter & $20 \mathrm{~mm}$ \\
\hline Dynamometer arm length & $195 \mathrm{~mm}$ \\
\hline Maximum Power & $5.2 \mathrm{~kW}(7 \mathrm{hp})$ \\
\hline Speed & $1500 \mathrm{rpm}$ \\
\hline Loading Device & Eddy current dynamometer \\
\hline Mode of starting & Manually cranking \\
\hline Injection Pressure & $220 \mathrm{kgf} / \mathrm{cm} 2$ \\
\hline Injection timing & $23^{\circ} \mathrm{C}$ before TDC \\
\hline
\end{tabular}




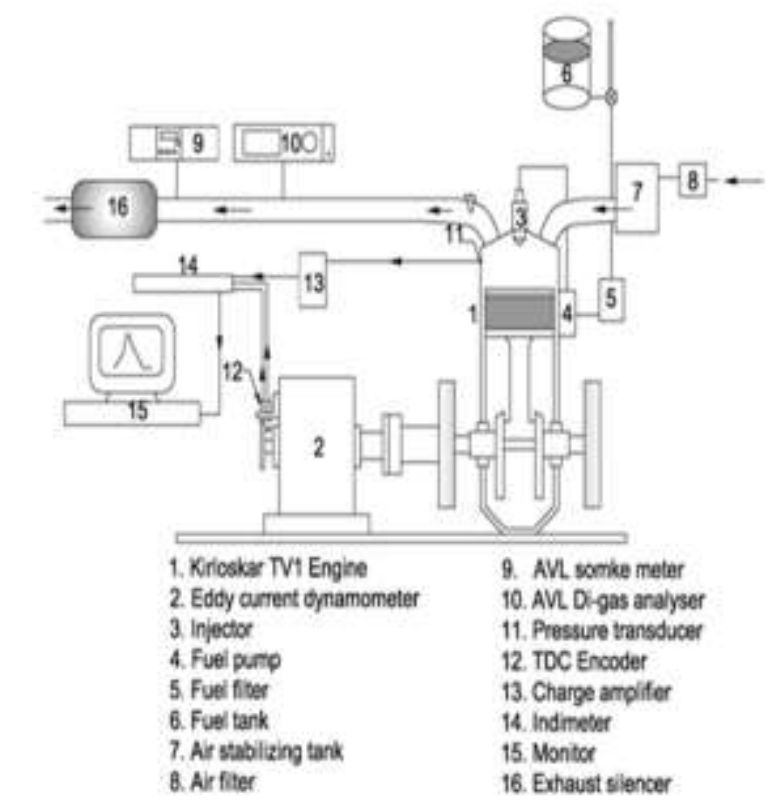

Figure 3.1. Experimental setup (Kirloskar TV-1 Engine)

\subsection{Experimental procedure}

The engine was allowed to run with neat diesel and biodiesel at a various loads for nearly 10 minutes to attain the steady state conditions. Then the following observations were made.

1. The water flow is started and maintained constant throughout the experiment.

2. The load, speed and temperature indicators were switched ON. The engine was started by cranking after ensuring that there is no load.

3. The engine was allowed to run at the rated speed of $1500 \mathrm{rpm} \mathrm{rev} / \mathrm{min}$ for a period of 20 minutes to reach the steady state.

4. The fuel consumption was measured by a stop watch for $10 \mathrm{ml}$ fuel consumption.

5. Smoke readings were measured using the AVL smoke meter at the exhaust outlet.

6. The amount of $\mathrm{NO}_{\mathrm{x}}$ was measured using AVL Di gas analyzer exhaust outlet.

7. The exhaust temperature was measured at the indicator by using a sensor.

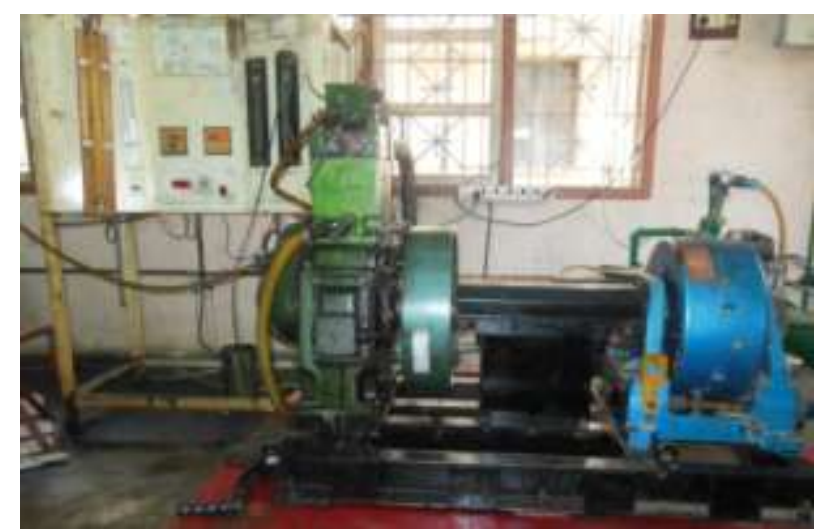

Figure 3.2.Photograph view of experimental setup (Kirloskar TV-1 Engine)

\section{Results And Discussion}

The results of the experimental investigation carried out have been furnished hereunder.

a) Brake Thermal Efficiency

Figure 1 shows the variations of brake thermal efficiency with brake power for various blends of biodiesel. From the graph it is clear that the brake thermal efficiency increases with increase in the percentage of bio-diesel blend. The brake thermal efficiency at full load of diesel and B25 biodiesel blend is 25.9, 25.5 respectively. The reason for decreasing brake thermal efficiency of the biodiesel blends is depends with lower calorific value, poor combustion, low volatility, high viscosity and density. 


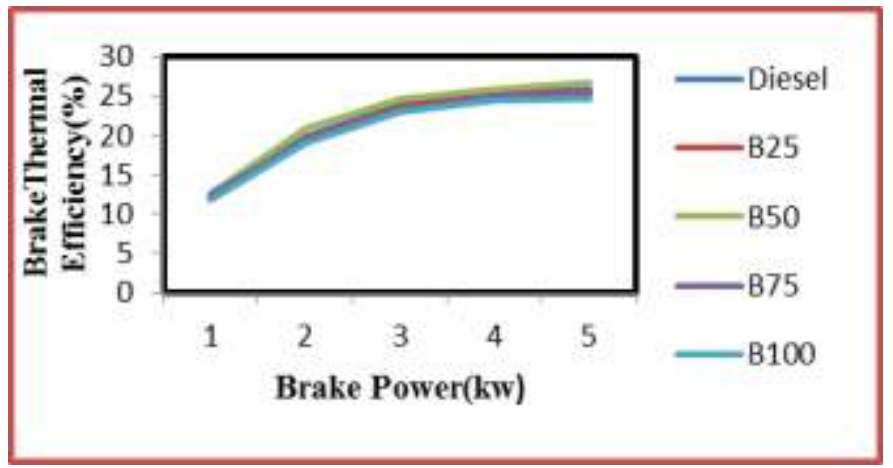

Figure a. Brake thermal efficiency against brake power

\section{b) Specific fuel consumption}

Figure 2 shows the variations of specific fuel consumption with brake power for diesel fuel with biodiesel. As brake power increases, SFC decreases. Among the diesel and various blends of jatropha biodiesel, the diesel fuel shows the lesser specific fuel consumption. It has shown by the value of $0.29 \mathrm{~kg} / \mathrm{kW}-\mathrm{hr}$ at full load condition. The SFC for the blend B25 has shown $0.31 \mathrm{~kg} / \mathrm{kW}-\mathrm{hr}$. The reason is complete combustion of the fuel achieved by the sole fuel.

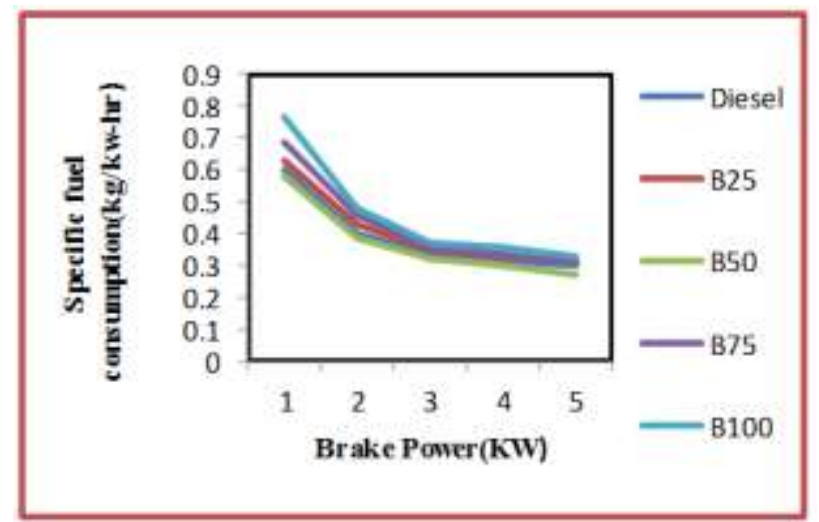

Figure b. Specific fuel consumption against brake power

\section{c) Oxides of Nitrogen}

The variations of $\mathrm{NO}_{\mathrm{x}}$ emission against brake power for jatropha biodiesel blends are shown in the Figure 3. The biodiesel blends of jatropha have the lower $\mathrm{NO}_{\mathrm{x}}$ emission when compare to diesel fuel. The blend $\mathrm{B} 25$ of has $5.1 \%$ lower of $\mathrm{NO}_{\mathrm{x}}$ emission when compare to diesel fuel. The $\mathrm{NO}_{\mathrm{x}}$ emission of diesel, blend B25 is 1118, 1062 ppm respectively with constant speed of the engine. This is due to the decrease in flame temperature due to the reduction in oxygen concentration in the combustion chamber. $\mathrm{NO}_{\mathrm{x}}$ emission depend up on the oxygen concentration during the combustion time. It is reported by Srinivasa Rao et.,2014 in his investigations and observed the same trends. The reason is shorter ignition delay; shorten the mixing time which leads to low burning rate that reduces the combustion temperature.

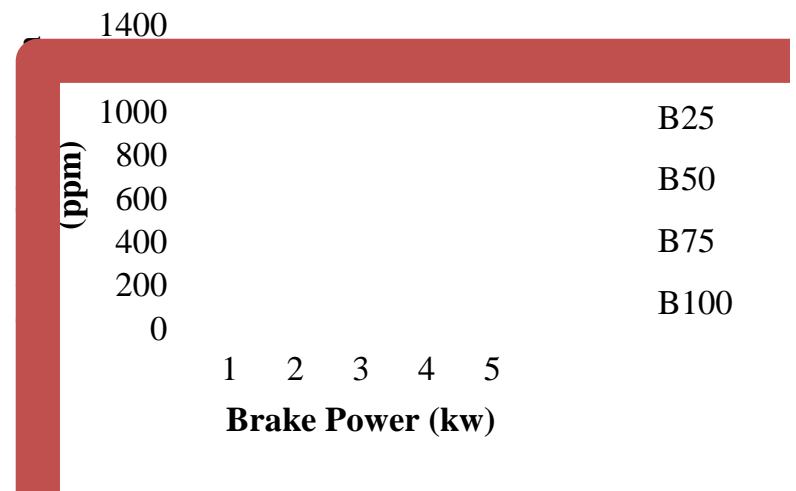

Figure c. Oxides of nitrogen against brake power 
d) Smoke density

The variation of smoke density against brake power for mahua biodiesel blends are shown in the Figure 4. From the graph it noticed that the biodiesel blends has higher smoke emission when compare to diesel fuel. The smoke emission of diesel, and blend B25 is 71HSU, 76.3HSU respectively with constant speed of the engine. This is mainly due to the high kinematic viscosity and poor volatility of jatropha biodiesel blend caused poor injection as a result of incomplete combustion.

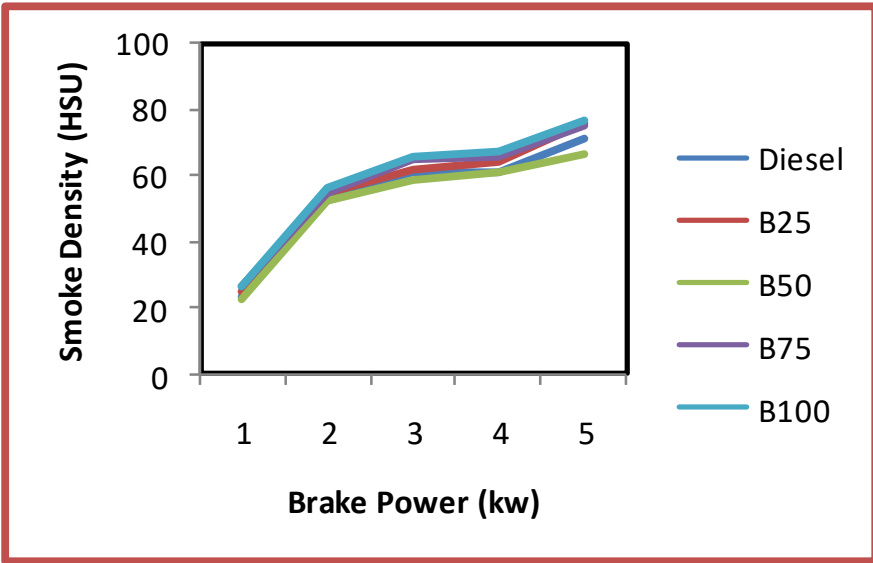

Figure d. Smoke density against brake power

\section{e) Carbon monoxide}

The variations of $\mathrm{CO}$ emission against brake power for jatropha biodiesel blends shown in the Figure 5 . From the graph it is seen that the biodiesel blends have higher $\mathrm{CO}$ emission when compare to diesel fuel. It has shown an increase of $2.85 \%$ of B25 blend when compared to that diesel fuel without any engine modification. $\mathrm{CO}$ emission is formed during the combustion process whenever charge is burned with an insufficient air supply with low in-cylinder temperature. $\mathrm{CO}$ emission is formed during the combustion process whenever charge is burned with an insufficient air supply with low in-cylinder temperature.

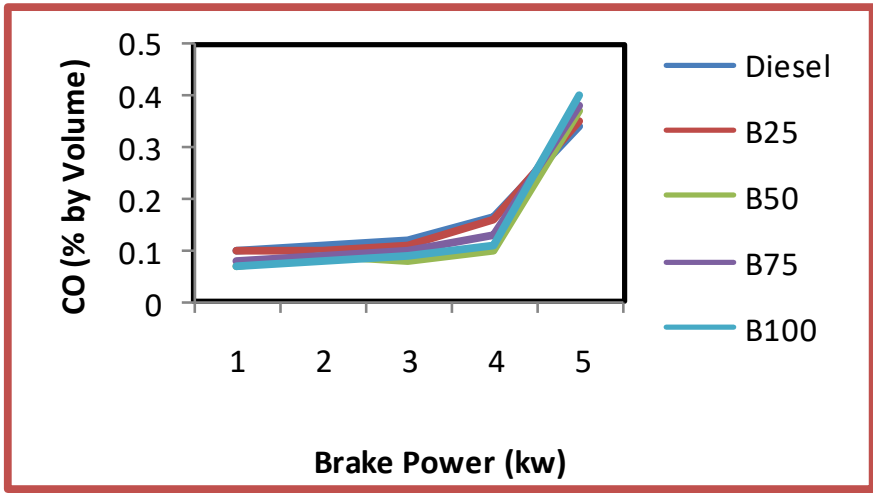

Figure e .Carbon monoxide against brake power

\section{f) Hydrocarbon}

The variations of $\mathrm{HC}$ emission against brake power for jatropha biodiesel blends are shown in the Figure 6. From the graph it is seen that the biodiesel blends have higher HC emission when compare to diesel fuel. The $\mathrm{HC}$ emission increases with increasing brake power of the engine. In this case of blend B25 shows $5.23 \%$ higher HC emission when compared to that of standard diesel fuel. The reason is high viscosity and boiling point of mahua biofuel. The heavier molecules present in the biofuel this has resulted in increased HC emission. 


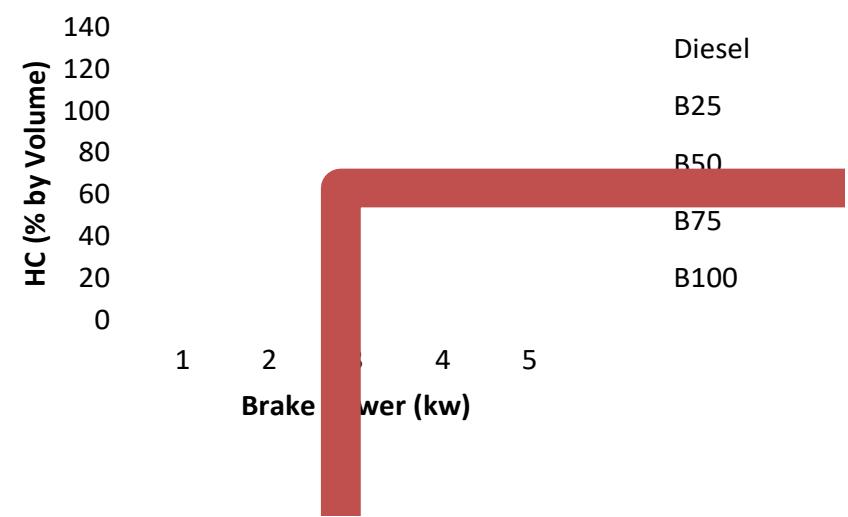

Figure f. Hydrocarbon against brake power

\section{Conclusion}

THE MAIN CONCLUSIONS OF THIS STUDY ARE;

1. The physical properties of the biodiesel produced from Jatropha seed oil through trans-esterification is measured and compared to that of diesel fuel.

2. Using of bio-diesel and its blend with methanol in varying proportions as a fuel in diesel engine causes improvement in engine performance and engine efficiency.

3. The blend $\mathrm{B} 25 \%$ shows significant reduction in $\mathrm{CO}, \mathrm{HC}$ and smoke emission when compared to that of other biodiesel blends.

4. The blend B25\% exhibit better performance and emissions characteristics when compared to that of other biodiesel blends.

5. The smoke emission for bio-diesel blend is significantly raised. In future in order to reduce the NOx emission, fuel additives may be employed to attain the desired result.

\section{References}

[1]. B.K. Barnwal, M.P. Sharma, "Prospects of biodiesel production from vegetable oils in India" Journal of Renewable and Sustainable Energy, Reviews, Vol.9, pp.363-378, 2005.

[2]. Ayhan Demirbas, Biodiesel production via non-catalytic SCF method and biodiesel fuel characteristics Journal of Energy Conversion and Management, Vol.47, pp.2271-2282, 2006.

[3]. Tint Tint Kywe, Mya Mya Oo, Production of Biodiesel from Jatropha Oil (Jatropha curcas) in Pilot Plant, World Academy of Science, Engineering and Technology, Vol.50, pp.477-483, 2009.

[4]. Dennis Y.C. Leung. Xuan Wu, M.K.H. Leung "A review on biodiesel production using catalyzed transesterification" Journal of Applied Energy, Vol.87, pp. 1083-1095, 2010.

[5]. Soo-Young No, Inedible vegetable oils and their derivatives for alternative diesel fuels in CI engines: A review, Journal of Renewable and Sustainable Energy Reviews, Vol.15, pp.131-149, 2011.

[6]. S.Antony Raja, D.S.Robinson smart, C.Lindon Robert Lee, Biodiesel production from jatropha oil and its characterization, Research Journal of Chemical Sciences, Vol.1(1), 2011.

[7]. Samodini S. Nevase, S.R. Gadge, A.K. Dubey, B.D. Kadu, Economics of biodiesel production from Jatropha oil, Journal of Agricultural Technology, Vol.8(2), pp.657-662, 2012.

[8]. Bobade S.N, Kumbhar R.R, Khyade V.B, Preperation of Methyl Ester (Biodiesel) from Jatropha Curcas Linn Oil, Research Journal of Agriculture and Forestry Sciences, Vol. 1(2), pp.12-19, 2013.

[9]. Ebtisam K. Heikal, Salah A. Khalil, Ismaeil K. Abdou, Jatropha Bio-Diesel Production Technologies, International Journal of Bioscience, Biochemistry and Bioinformatics, Vol. 3, pp.288-292, 2013.

[10]. Nurrul Rahmah Binti Mohd Yusoff, Sulaiman bin Hj Hasan, Nor Hazwani binti Abdullah,

[11]. Process to Produce Biodiesel Using Jatropha Curcas Oil (JCO), International Journal of Materials Science and Engineering, Vol.1(2), 2013.

[12]. Godwin Kafui Ayetor, Albert Sunnu, Joseph Parbey, Effect of biodiesel production parameters on viscosity and yield of methyl esters: Jatropha curcas, Elaeis guineensis and Cocos nucifera, Alexandria Engineering Journal, Vol.54, pp.1285-1290, 2015.

[13]. Nirza Fabiola Castro Gonzales, International experiences with the cultivation of Jatropha curcas for biodiesel production, Energy, Vol.112, pp.1245-1258, 2016.

[14]. A.Kalaiyarasan, C.Srinivasan, R.Ramesh, S.Sasidharan, S.Palanisamy., Oxidation of Soot Particles in Diesel Exhaust Emission using Plasma Source., International Journal for Scientific Research \& Development., Volume 4 Issue Issue 09, 2016 | ISSN (online): 2321-061 